\title{
O Centenário de Guerreiro Ramos e sua Atualidade para o Ensino de Ciências Sociais no Brasil
}

\author{
Amurabi Oliveira ${ }^{1}$ \\ Universidade Federal de Santa Catarina, Florianópolis, Brasil \\ E-mail: amurabi_cs@hotmail.com
}




\section{Resumo}

Nos últimos anos, a obra de Alberto Guerreiro Ramos (1915-1982) tem sido constantemente revisitada, o que se conecta às transformações vivenciadas nas Ciências Sociais brasileiras nos últimos anos. Porém, um aspecto ainda pouco explorado tem sido sua contribuição para o campo do ensino, mais especificamente do ensino de Ciências Sociais. Nesse artigo, busca-se analisar a contribuição de Guerreiro Ramos para a discussão sobre o ensino de Ciências Sociais, tomando como fio condutor principal suas ideias expostas em Cartilha Brasileira do Aprendiz de Sociólogo (1954) destacando a atualidade das questões expostas.

Palavras-chave: Alberto Guerreiro Ramos. Pensamento Social Brasileiro. Ensino de Ciências Sociais.

\section{Abstract}

In recent years the work of Alberto Guerreiro Ramos (1915-1982) has been constantly revisited, which is connected to the changes experienced in the Brazilian Social Sciences in recent years. But a little explored aspect has been his contribution to the the field of teaching, specifically the Teaching of Social Sciences. In this article I seek to analyze the contribution of Guerreiro Ramos to the discussion about Teaching Social Sciences, taking as main conductor wire his ideas exposed in the Brazilian Handbook of the Sociologist's Apprentice (1954), highlighting the relevance of the questions posed.

Keywords: Alberto Guerreiro Ramos. Brazilian Social Thought. Teaching of Social Sciences. 


\section{Introdução}

trabalho do baiano Alberto Guerreiro Ramos (1915-1982) foi mar-
cado por sua originalidade, vigor e pelas polêmicas, especialmente aquelas desdobradas entre as décadas de 1950 e 1960. Sua apreensão tem passado por fases distintas, possuindo nos últimos tempos uma crescente revisita que demarca o lançamento de novas e originais abordagens sobre seu trabalho que apontam para sua atualidade, mas que se relacionam também com as mudanças mais amplas que podem ser observadas no próprio campo das ciências sociais.

Sua cor - era um homem mulato - e sua origem geográfica no meu entender se ligam de forma direta à forma como ele percebeu o mundo e a produção do conhecimento, pois ao migrar ainda jovem em 1939 para o então Distrito Federal, naquele momento Estado da Guanabara, Guerreiro Ramos vivenciou o destino que estava reservado a boa parte da população brasileira, que se deslocava para a região que gravitava em torno do circuito Rio - São Paulo. Guerreiro Ramos vivenciou dessa forma os "dois brasis", aquele que representara o Brasil arcaico e do atraso, substanciado no Nordeste e no sertanejo, tão descritos em Os Sertões, obra publicada por Euclides da Cunha em 1902, e o outro moderno e pulsante representado pelos grandes centros urbanos que passaram a representar o novo eixo político e econômico do país.

A data de sua mudança para o sudeste coincide com o período do Estado Novo que, com a proposta de centralização das decisões na capital federal, punha em xeque o pacto federativo, ao menos no formato que havia se acomodado em relação às oligarquias locais. Esta questão que busco ressaltar brevemente nessa introdução mostra-se relevante para minha compreensão da produção do Guerreiro Ramos, 
pois muito tem se chamado a atenção para o fato de seu trabalho poder ser compreendido como inserido dentro do que se tem denominado de pensamento periférico (Maia, 2015), penso que Guerreiro Ramos estava numa posição periférica também a partir da sua cor, e da origem geográfica, sendo esta última uma das questões mais relevantes para o Brasil que emergia no começo do século XX (Albuquerque Junior, 2007).

O que se quer dizer com isso é que as experiências sociais vivenciadas por Guerreiro Ramos foram fundamentais na constituição de seu pensamento, e que possibilitaram o desenvolvimento da percepção dos limites das teorias existentes para a apreensão do social em dadas realidades.

Neste breve trabalho busca-se pensar a atualidade das discussões de Guerreiro Ramos para o ensino de Sociologia no Brasil hoje, tema que tem ganhado relevância com a reintrodução desta ciência no currículo escolar a partir de 2008. Para tanto, as atenções estarão voltadas para o exame do livro Cartilha Brasileira do Aprendiz de Sociólogo (1954), dialogando, portanto, não apenas com o ensino de Sociologia no sentido mais estrito, mas também com a formação dos cientistas sociais no Brasil.

Na primeira parte foi realizada uma breve apresentação de algumas ideias que considero centrais para a compreensão do tipo de pensamento social que este autor produziu, ainda que não caiba aqui realizar um exame minucioso de seu trabalho devido aos limites e ao foco desse artigo. Na segunda seção desse trabalho é que me voltarei de forma mais incisiva para sua discussão sobre o ensino de sociologia, o que será realizado em diálogo com a produção da comunidade acadêmica contemporânea que discute tal questão.

\section{O Pensamento de Guerreiro Ramos}

Se numa interpretação a origem geográfica mostra-se relevante para a compreensão do pensamento do autor aqui analisado, assim como o fato de ser mulato e migrante, considera-se que não menos relevante para essa questão foi a formação intelectual que ele recebeu, especialmente no que diz respeito àquela da Faculdade Nacional de Filosofia. 
O curso de Ciências Sociais da Faculdade Nacional de Filosofia, que integrava a Universidade do Brasil (criada pela Lei n. 452 de 5 de julho de 1937) demarcava uma continuidade em relação àquele que existiu na Universidade do Distrito Federal (UDF), criado em 1935, tendo sido o primeiro nessa área fora de São Paulo.

Não se pode olvidar que a UDF foi em grande medida um projeto do também baiano Anísio Teixeira (1900-1971), que se distava substancialmente daquele existente na Universidade de São Paulo, ou ainda na Escola Livre de Sociologia e Política de São Paulo, nas quais foram criados os primeiros cursos de Ciências Sociais, em 1934 e 1933 respectivamente. Como assinala Meucci (2015, p. 128):

[...] o desenvolvimento da ciência estava essencialmente ligado à democratização do acesso à cultura. Trata-se à princípio, de um projeto universitário muito distinto da Universidade de São Paulo (USP), cujo leitmotiv foi essencialmente a formulação de elites intelectuais e políticas capazes de orientar o povo.

Claro que parte desse projeto já havia se esvaído quando Guerreiro Ramos chegou ao curso de Ciências Sociais, Anísio Teixeira já não estava mais a frente dele, e em 1939 a UDF já havia sido incorporada à Universidade do Brasil. Porém, creio que a formação em um curso que se originou num projeto distinto daquele existente em São Paulo é relevante nesse caso. Em termos cronológicos não é menos importante destacar que Guerreiro Ramos constitui essa primeira geração de sociólogos profissionais formados no Brasil, pois até então os docentes da área das Ciências Sociais, via de regra, eram intelectuais autodidatas. Finalizado seu curso em 1942 no ano seguinte ele tentou ingressar como docente nessa Faculdade, pois surgiram algumas vagas com o retorno de alguns professores para a Europa.

Foi indicado para assumir duas delas, a de sociologia e a de ciência política, mas foi preterido, na primeira, por L.A. Costa Pinto e, na segunda, por Vítor Nunes Leal. Como forma de compensá-lo, San Tiago Dantas, seu amigo pessoal, e à época no exercício do cargo de Diretor da faculdade, ofereceu-lhe trabalho no Departamento Nacional da Criança (DNCr), onde lecionou cursos sobre puericultura, tendo também sido nomeado, 
interinamente, para o Departamento Administrativo do Serviço Público (DASP), quanto então a temática administrativa passou a lhe atrair com maior força. (Azevedo, 2006, p. 180)

A partir dessa inserção profissional, não apenas a ideia de administração como também de planificação passa a lhe atrair, não à toa, Villas Boas (2006) compreende que ele acabou por integrar o que ela denomina de "geração mannheimiana" de sociólogos brasileiros, para a qual fazer ciência é fazer história.

Se para Miceli (1989) a proximidade com "instituições não acadêmicas" constituiu um problema na formação das ciências sociais no Rio de Janeiro, o que incluiria o Instituto Superior de Estudos Brasileiros (ISEB) do qual Guerreiro Ramos fazia parte. Penso que, por outro lado, tal aproximação possibilitou a elaboração de uma percepção muito particular sobre os problemas brasileiros, que por sua vez impactou na construção de uma perspectiva engajada de produção do conhecimento científico ${ }^{2}$.

Sem embargo, é importante frisar que não se acredita com isso que houvesse uma defesa por parte de Guerreiro Ramos de que o engajamento se opusesse à construção do conhecimento científico no campo das Ciências Sociais; pois parece que o que estava em questão era qual a finalidade desse conhecimento. Em países como o Brasil, as ciências sociais teriam finalidades muito próprias: a) a elaboração de teorias, conceitos e ideias que possibilitassem a nação a compreenderse a si mesma; b) decifrar seus problemas (Guerreiro Ramos, 1954).

Atingir essas finalidades perpassaria, necessariamente, a discussão sobre o Ensino de Sociologia no Brasil, especialmente no âmbito da formação das próximas gerações de sociólogos. O que demandaria a superação de uma situação que ele percebia como crítica na sociologia brasileira, na qual os sociólogos estariam mais preocupados em se informar da produção estrangeira que em compreender sua própria realidade. Segundo ele:

[...] a formação do sociólogo brasileiro ou latinoamericano consiste, via de regra, num adestramento para o conformismo, para a disponibilidade da inteligência em face das teorias. Ele aprende a receber prontas as 
soluções, e quando se defronta com um problema de seu ambiente, tenta resolvê-lo confrontando textos, apelando para as receitas de que se abeberou nos compêndios. Adestrado para pensar por pensamentos feitos, torna-se frequentemente, quanto aos sentimentos e à volição, um répetiteur, isto é, sente por sentimentos feitos, quer por vontades feitas, como diria Péguy. (Ramos, 1954, p. 19-20)

Com isso não se quer dizer que a ciência não devesse ter um caráter universal, porém, isso não deveria impedir que ela se diferenciasse nacionalmente (Ramos, 1957). O que ele estava combatendo seria o que denominou de "sociologia enlatada". Tal combate perpassaria necessariamente, nos termos da redução sociológica, uma postura conscientemente engajada dos cientistas sociais com seus contextos. Para Ramos (1958, p. 46):

A redução sociológica não implica em isolacionismo, nem exaltação romântica do local, regional ou nacional. É ao contrario dirigida a uma aspiração ao universal mediatizado, porém, pelo local, regional ou nacional. Não se pretende opor-se à prática das transplantações mas se quer submetê-las a apurados critérios de seletividade. Uma sociedade onde se desenvolve a capacidade de autoarticular-se tornar-se conscientemente seletiva.

As considerações sobre o Ensino de Sociologia presentes no pensamento desse intelectual tocam, portanto, a questão do combate a uma sociologia inautêntica. Nesse sentido, podemos relacionar as questões postas por Guerreiros Ramos com algumas discussões recentes em torno das Teorias do Sul (Connel, 2007). Como nos indica Maia (2015, p. 53):

Se, por um lado, é antiga a linhagem de pensadores brasileiros que diagnosticara o caráter supostamente artificial e "importado" da vida intelectual brasileira (Brandão, 2005), é forçoso reconhecer que a linguagem e o vocabulário utilizados por Guerreiro Ramos para fazer esse mesmo ponto são novos. Há uma decidida abordagem geopolítica que coloca o problema da colonização e do eurocentrismo em lugar mais central do que, digamos, em Visconde do Uruguai ou em Alberto Torres, dois conhecidos pensadores associados a essa vertente crítica. 
Pensadores não europeus estavam praticamente ausentes do horizonte desses homens, ainda fortemente orientados para a tradição cultural europeia.

Considera-se que tais questões ainda não foram superadas na discussão da Sociologia brasileira, pelo contrário, encontram-se mais atuais que nunca dado a crescente relevância e impacto dos estudos pós-coloniais nas ciências sociais (Costa, 2006; Martins, 2013).

Esta breve apresentação do trabalho de Guerreiro Ramos, aqui insuficientemente aprofundada devido aos limites desse trabalho, serve de gancho para a próxima seção desse artigo, pois, para compreendermos sua análise acerca do Ensino de Sociologia no Brasil é necessário ter em mente o papel dessa ciência e do sociólogo na compreensão desse intelectual.

\section{O Ensino de Sociologia no Brasil: um olhar crítico e engajado}

Quando Guerreiro Ramos publicou Cartilha Brasileira do Aprendiz de Sociólogo em 1954 a Sociologia não estava mais presente no currículo escolar de forma obrigatória, pois sua trajetória ascendente que começou com a Reforma Rocha Vaz em 1925 havia sido interrompida com a Reforma Capanema em 1942 (Oliveira, 2013). No mesmo ano, durante o I Congresso Brasileiro de Sociologia, Florestan Fernandes havia proferido a palestra $O$ Ensino de Sociologia na Escola Secundária Brasileira (Fernandes, 1980), e apesar de os dois textos terem sido veiculados na mesma época e mencionado a mesma temática, problematizando a realidade do ensino de sociologia no Brasil, aquele não teve a mesma circulação e reconhecimento por parte da comunidade de cientistas sociais que vêm debatendo o ensino de sociologia nos últimos anos. É interessante aqui analisar as questões postas por Guerreiro Ramos para então lançar hipóteses sobre as razões que fazem com que seu trabalho não tivesse grande repercussão em meio a essa comunidade de pesquisadores.

É relevante rememorar desde já que a o trabalho aqui analisado constitui uma resposta às críticas que Guerreiros Ramos recebeu durante o II Congresso Latino-Americano de Sociologia, realizado no Rio de 
Janeiro e em São Paulo em 1953. Nesse evento, ele presidiu a Comissão de Estruturas Nacionais e Regionais, tendo realizado sete propostas que foram rechaçadas. Destaca-se aqui a segunda delas:

A organização do ensino de sociologia nos países latinoamericanos deve obedecer ao propósito fundamental de contribuir para a emancipação cultural dos discentes, equipando-os de instrumentos intelectuais que os capacitem a interpretar, de modo autêntico, os problemas das estruturas nacionais e regionais a que se vinculam. (Ramos, 1954, p. 16)

Essas, assim como as outras seis proposições, foram refutadas por 22 votos contra 9, e segundo o autor ele ainda foi agredido com demonstração de ódio e desapreço por parte de alguns de seus opositores. Interessante notar que no capítulo da Cartilha dedicado a este assunto o título mostra-se bastante provocativo "O Ensino de Sociologia no Brasil, um caso de Geração Espontânea?", com isso ele anuncia prontamente o tom crítico que assume sobre a questão, querendo dizer com isso que a sociologia surge através de um processo cooperativo e cumulativo.

Porém, ele ressalta que reconhece o mérito de várias agências brasileiras de ensino e prática sociológica, destacando-se em São Paulo a Escola de Sociologia e Política, o Departamento de Sociologia e Antropologia na Faculdade de Filosofia, o Instituto de Administração da Faculdade de Ciências Econômicas e Administrativas e no Rio, a Escola de Administração Pública da Fundação Getúlio Vargas, os cursos do DASP, além de experiências com a cadeira de sociologia no Rio Grande do Sul e no Paraná, e de Antropologia na Bahia. Tais exemplos servem para confirma sua perspectiva de que no Brasil, assim como em muitos países da América - Latina, a proliferação de cátedras de sociologia constituiria um perigo, na medida em que ele estava convencido de que não havia condições de haver uma prática de ensino dessa matéria de boa qualidade a não ser em pequena escala.

Na literatura mais recente sobre ensino de sociologia há inúmeras referências ao texto de Florestan Fernandes supracitado, porém, esse trabalho seminal de Guerreiro Ramos é solenemente ignorado, o que pode ser compreendido a partir de uma gama de fatores. Primeiramente 
é válido considerar o lugar da enunciação desses diversos discursos, dentro da complexa geopolítica acadêmica o paradigma uspiano de ciências sociais veio a prevalecer em outras universidades do Brasil; segundo, a apropriação de Guerreiro Ramos nas ciências sociais brasileiras deve ser considerada aí, pois como nos indica Maia (2012), ao passo que nas pesquisas realizadas no âmbito dos programas de administração ele perdura como um relevante referencial teórico, no caso das ciências sociais ele tende a surgir como objeto de estudos, normalmente sob o difuso conceito de pensamento social brasileiro, que como nos aponta Botelho (2010), marca-se por uma profunda heterogeneidade, sendo essa classificação mais um exercício de atribuição que de inferência; por fim, e acredita-se que esse é o argumento principal para o raciocínio que se pretende desenvolver aqui, a postura crítica que o ator assume com relação ao ensino de sociologia realizado especialmente entre as décadas de 1930 e 1940 não conflui para os interesses as entidades científicas e associações profissionais que passaram a se engajar pelo retorno da sociologia no currículo escolar, tratava-se de uma análise que era bem-vinda, pois não confluía com os interesses dos agentes naquele momento.

Em sua análise sobre o ensino de sociologia naquele período, Guerreiro Ramos chama de desastrosa e imprevidente a política educacional que possibilitou um verdadeiro "surto de catedráticos da referida disciplina" no Brasil, que não estando preparados para tal feito tiveram que improvisar.

Sua crítica perpassa ainda a produção dos manuais de sociologia que eram utilizados na prática escolar, que como é bem sabido teve uma rápida expansão entre as décadas de 1920 e 1940, tendo em vista que a sociologia estava presente tanto nos cursos preparatórios para o acesso aos cursos superiores ${ }^{3}$, quanto na formação docente nas escolas normais. Segundo Ramos (1954, p. 46-47):

[...] nossos autores de compêndios não têm, salvo raríssimas exceções, uma experiência vivida dos problemas e assuntos de que tratam. Seus textos escolares não são propriamente fruto de meditação dos assuntos. Resultam, com frequência, de glosas, paralelos, pastiches e transcrições de obras estrangeiras. Julgo que 
essa deficiência da maioria de nossos livros escolares se explicam pelas próprias condições objetivas do País.

Os professores brasileiros de sociologia, em grande parte, têm exercido a cátedra por acaso. Ordinariamente, tem sido um fator aleatório em suas vidas o que os leva a ser professor de sociologia. Não se prepararam para tal. Aqui as cátedras de sociologia não surgiram para consagrar uma tradição militante de trabalho pedagógico, como é a regra em todos os países avançados. As cátedras aparecem de modo intempestivo e foram providas, inicialmente, mais ou menos, por pessoas que, no momento, ou eram diletantes, quanto muito; ou desconheciam completamente os estudos de sociologia. Muitos foram estudar a matéria depois de nomeados professores; durante algum tempo, ao menos, foram nos seus postos verdadeiros simuladores, aparentando um saber que realmente não possuíam.

Essas assertivas em parte são confirmadas pela pesquisa de Meucci (2011), que ao examinar a formação dos autores de manuais de sociologia entre as décadas de 1920 e 1940 no Brasil, aponta para o perfil autodidata como recorrente. Porém, apesar disso, em muitos manuais, a autora encontrou sugestões de atividades diversas que incluíam consulta bibliográfica, trabalho de campo, aplicação de questionário e inquéritos sociais etc., o que dista da perspectiva de Guerreiro Ramos que aponta para um ensino apartado dos problemas reais que permeavam a sociedade nacional.

Ele reconhece ainda as mudanças em curso com o advento de uma nova geração de professores de sociologia, agora versados nas ciências sociais, com formação universitária para tanto, o próprio Guerreiro Ramos estaria incluído nesse grupo.

Percebe-se ainda que sua crítica aos manuais escolares de sociologia só pode ser compreendida em sua plenitude ante sua compreensão de que há uma "sociologia enlatada", portanto inautêntica. Para ele:

Há, hoje, no Brasil, duas sociologias: uma enlatada, que se faz, via de regra, nos quadros escolares e no âmbito confinado de reuniões e entidades particularistas de caráter acadêmico; e outra que se exprime predominantemente em comportamentos e que se pensa, por assim dizer, com as mãos, no exercício de atividades executivas e de 
aconselhamento nos quadros dos negócios privados e governamentais. A primeira, em larga escala, tem sido uma percepção ilusória da realidade do país; a segunda, espécie de crisálida, emerge da vida comunitária nacional e se encaminha no sentido de tornar-se uma autoconsciência das leis particulares da sociedade brasileira (Ramos, 1957, p. 120 grifo do autor)

A presença dessa "sociologia enlatada" nos diversos manuais refletiria o próprio ensino das ciências sociais no ensino universitário, uma vez que quando os cursos de ciências sociais foram criados, na perspectiva do autor, apenas dois brasileiros poderiam ser considerados sociólogos sistemáticos originais: Oliveira Viana (1883-1951) e Pontes de Miranda (1892-1979), mas que teriam tido uma influência nula sobre o ensino de sociologia no momento de institucionalização do ensino de sociologia no Brasil.

Para reforçar seus argumentos, Guerreiro Ramos compara ainda o processo de institucionalização do ensino de sociologia no Brasil com aquele que teria ocorrido em outros países, como Estados Unidos, Rússia e Índia, realizando um exercício comparativo de caráter mais amplo até hoje ainda incipiente no debate sociológico brasileiro, o que demonstra o vigor e a originalidade de seu pensamento.

Acaba por fim por se deter um pouco mais no caso americano, apontando como o ensino de sociologia naquele país representou certo estado de amadurecimento do debate intelectual nessa área. Penso que nesse ponto podemos questionar os argumentos utilizados pelo autor tendo por base o debate que tem se instaurado nos Estados Unidos acerca do ensino de sociologia, pois, autores como DeCesare (2014), num movimento de revisita da própria história do ensino de sociologia nos Estados Unidos, aponta para a fragilidade da prática pedagógica dessa disciplina nas escolas americanas no momento de sua institucionalização, aproximando-se mais de uma "educação cidadã" que de um ensino de uma disciplina científica.

Acredita-se, portanto, que haja mais pontos em comum em termos de desafios que se colocaram no processo de institucionalização do ensino de sociologia, especialmente no nível escolar, entre o Brasil e os "países avançados", ainda que não se possa negar a existência de 
condições objetivas distintas em termos de produção do conhecimento, especialmente no que tange às universidades.

Apesar das duras e intensas críticas ao ensino de sociologia, considera-se que Guerreiro Ramos via a sociologia escolar como um campo de possibilidades em aberto, compreendendo que

[... ] o ensino escolar de sociologia, a despeito desta ainda não ter se depurado da alienação em relação à realidade do país e ainda não possuir profissionais capazes, seria uma forma de tornar acessível esse saber ao senso comum, tornar-se efetivamente um 'saber de salvação. (Bariani Junior, 2003, p. 17)

Acredita-se que parte da atualidade de seu pensamento se deva à não superação de certos dilemas no âmbito da própria formação dos professores de sociologia, sem contar aqui a predominância atual de profissionais com outras formações acadêmicas atuando no ensino desta ciência. Como indica Maio (2012, p. 265):

Um estudante de graduação em Ciências Sociais em qualquer universidade brasileira dificilmente deixará seu curso sem ter lido algo de Karl Marx, Max Weber e Émile Durkheim. Em geral, estes autores são estudados nas primeiras disciplinas de formação, nas quais se aprende que tal trindade forma os clássicos da disciplina. Entretanto, pouquíssimos formandos refletirão, em algum momento, sobre as razões que presidiram a construção de tal cânone. Em boa parte das vezes, a nossa compreensão ordinária da história da sociologia limita-se a registrar a narrativa consagradora de tal literatura, pouco se perguntando sobre os motivos que possam explicar o jogo de seleções/rejeições que governa a escolha dos clássicos.

Não estando esse cenário superado, ainda que sejam inegáveis os avanços vivenciados pelas ciências sociais brasileiras nas últimas décadas, acredita-se que as questões lançadas por Ramos ainda se fazem pertinentes, o que inclui sua perspectiva acerca da finalidade do ensino da sociologia.

O que se pede ao ensino de sociologia é que ele desenvolva no educando a capacidade de autonomia e 
assenhoramento das forças particulares da sociedade em que vive. O ensino da sociologia não deve distrair o educando da tarefa essencial de promoção da autarquia social do seu país.

É necessário que o trabalho de campo, complementar da instrução teórica, se encaminhe para o adestramento dos aprendizes para a realização dos trabalhos mais necessários ao desenvolvimento das estruturas nacionais e regionais. (Guerreiro Ramos, 1954, p. 56-57)

Dada a tarefa hercúlea que Guerreiro Ramos atribui ao ensino de sociologia, penso que sua distância com relação à geração de professores que atuou nas escolas brasileiras nas décadas de 1930 e 1940 - o autor destaca especialmente o período entre 1936 e 1942 - é menor do que a imaginada.

A volta da sociologia ao currículo escolar nos anos 2000 em grande medida aventa uma aproximação, no meu entender, com o tipo de ensino criticado por Ramos, ao menos ao nível dos documentos oficiais e dos manuais (livros didáticos) existentes. De tal modo que a crítica elaborada por esse grande pensador social se mostra não apenas atual como também necessária.

\section{Considerações Finais}

Dentre as várias possibilidades de se abordar o pensamento multifacetado de Guerreiro Ramos, optou-se por uma ainda pouco explorada, que remete suas contribuições para o campo do ensino, especialmente do ensino das Ciências Sociais. Ainda que essa temática não tenha sido o alvo preferencial de sua produção acadêmica, é possível compreender que todas as suas análises e críticas acerca das Ciências Sociais podem ser incorporadas na discussão mais ampla sobre o ensino de tais ciências, especialmente no caso brasileiro.

Se por um lado, suas contribuições ainda não se encontram amplamente difundida na comunidade que tem se formado de cientistas sociais dedicados à discussão sobre o ensino, por outro, as mudanças vivenciadas nas ciências humanas e sociais têm possibilidade a elaboração de novos olhares sobre o legado intelectual de Guerreiro Ramos, 
com destaque para um amplo diálogo com os estudos pós-coloniais e subalternos.

Ainda no que tange à atualidade de suas críticas, penso que não superamos completamente o modelo de uma "sociologia enlatada", especialmente no campo formativo dos cientistas sociais. A replicação de modelos teóricos e explicativos ainda persiste, ainda que seja possível reconhecer as transformações pelas quais tem passado o debate nesse campo, bem como o esforço de diversos intelectuais, que ainda que se coloquem em termos distintos daqueles postos por Ramos têm se engajado na elaboração de uma ciência social nacional, sem com isso perder a pretensão de universalismo.

Também o cenário do próprio ensino das Ciências Sociais na Educação Básica se alterou substancialmente, pois, apesar da persistência da presença de professores que não possuem formação nessa área e que atuam na docência da Sociologia no Ensino Médio, seria leviano afirmar que o grau de improviso é o mesmo daquele observado por Ramos em seu tempo. Há uma presença crescente de cientistas sociais com formação na área atuando nas escolas, o que se dá de forma concomitante à expansão do número de cursos de formação inicial nesse campo.

A crítica de Ramos, portanto, mostra-se pulsante e contemporânea, todavia, um exame mais minucioso do conjunto de sua obra, elaborado em conjunto com uma análise aprofundada do cenário atual das Ciências Sociais no Brasil, poderia nos possibilitar uma crítica mais incisiva aos atuais modelos formativos existentes nas ciências sociais brasileiras, um exercício que me parece ser cada vez mais necessário ante a crescente expansão quantitativa de tais cursos e a presença incisiva de tais ciências na Educação Básica.

\section{Notas}

1 Doutor em Sociologia pela Universidade Federal de Pernambuco (UFPE), Professor da Universidade Federal de Santa Catarina (UFSC), Pesquisador do CNPq.

2 Numa crítica contundente ao trabalho de Miceli, Reesink e Campos (2014) apontam que esse trabalho mais do que narrar a história das Ciências Sociais no Brasil busca elaborar uma narrativa para legitimar a consolidação e implementação e consolidação da hegemonia paulista, através tanto da inclusão hierárquica quanto da exclusão desqualificadora. 
3 Foi com a Reforma Francisco Campos em 1931 que a sociologia passou a figurar de forma obrigatória nesses cursos complementares, que outorgavam àqueles que os concluíam o título de Bacharel em Ciências e Letras.

\section{Referências}

ALBUQUERQUE JÚNIOR, Durval Muniz. Preconceito contra a origem geográfica e de lugar: as fronteiras da discórdia. São Paulo: Cortez, 2007.

AZEVEDO, Ariston. A Sociologia Antropocêntrica de Alberto

Guerreiro Ramos. 2006. 354 f. Tese (Doutorado) - Sociologia Política do Centro de Filosofia e Ciências Humanas - Universidade Federal de Santa Catarina, Florianópolis, 2006.

BARIANI JUNIOR, Edison. A sociologia no Brasil: uma batalha, duas trajetórias (Florestan Fernandes e Guerreiro Ramos). 2003. $111 \mathrm{f}$. Dissertação (Mestrado em Sociologia) - Faculdade de Ciências e Letras da Universidade Estadual Paulista, Araraquara, 2003.

BOTELHO, André. Passado e futuro das interpretações do país. Tempo Social, [S.l.], v. 22, n. 1, p. 47-66, 2010.

CONNELL, Raewyn. Southern theory: the global dynamics of knowledge in social science. London: Polity Press, 2007.

COSTA, Sergio. Desprovincializando a sociologia: a contribuição póscolonial. Revista Brasileira de Ciências Sociais. Revista Brasileira de Ciências Sociais, [S.l.], v. 21, n. 60, p. 117-134, 2006.

DECESARE, Michael. 95 anos do Ensino de Sociologia no Ensino Médio. Educação \& Realidade, [S.l.], v. 39, n. 1, p. 113-137, 2014.

FERNANDES, Florestan. A sociologia no Brasil: contribuição para o estudo de sua formação e desenvolvimento. Petrópolis: Vozes, 1980.

MAIA, João Marcelo Ehlert. A sociologia periférica de Guerreiro Ramos. Caderno CRH, [S.l.], v. 28, n. 73, p. 47-58, 2015.

. Reputações à brasileira: o caso de Guerreiro Ramos. Sociologia $\mathbf{8}$ Antropologia, [S.l.], v. 2, n. 4, p. 265-291, 2012.

MARTINS, Paulo Henrique. La Sociología y el espejo de la colonialidad en América Latina. Revista Horizontes Sociológicos, [S.l.], v. 1, n. 1, p. 33 46, 2013.

MEUCCI, Simone. Artesania da sociologia no Brasil: contribuições e interpretações de Gilberto Freyre. Curitiba: Appris, 2015.

- Institucionalização da Sociologia no Brasil: primeiros

manuais e cursos. São Paulo: Hucitec; Fapesp, 2011. 
MICELI, Sergio. Condicionantes do desenvolvimento das ciências sociais. In: MICELI, Sergio. (Org.). História das ciências sociais no Brasil. São Paulo: EditoraVértice/Idesp/Finep, 1989. p. 72-110.

OLIVEIRA, Amurabi. Revisitando a história do ensino de Sociologia na Educação Básica. Acta Scientiarum. Education, [S.l.], v. 35, n. 2, p. 179 $189,2013$.

RAMOS, Alberto Guerreiro. Cartilha Brasileira do Aprendiz de Sociólogo. Rio de Janeiro: Est. De Artes Gráficas C. Mendes Jr., 1954. Introdução Crítica à Sociologia Brasileira. Rio de Janeiro: Andes, 1957.

A Redução Sociológica: introdução ao estudo da razão sociológica. Rio de Janeiro: Iseb, 1958.

REESINK, Misia L.; CAMPOS, Roberta B. C. A Geopolítica da Antropologia no Brasil: ou como a província vem se submetendo ao Leito de Procusto. In: SCOTT, Parry; CAMPOS, Roberta Bivar; PEREIRA, Fabiana. (Org.). Rumos da Antropologia no Brasil e no Mundo: geopolíticas disciplinares. Recife-PE: Editora UFPE-ABA, 2014.

VILLAS BÔAS, Glaucia. Mudança provocada: passado e presente no pensamento sociológico brasileiro. Rio de Janeiro: Editora FGV, 2006.

Recebido em 16/02/2016

Aceito em 1\%03/2016 